\title{
Analysis of floodable areas of the Angara river
}

\author{
Gachenko Andrey ${ }^{1, *}$, Hmelnov Alexey ${ }^{2}$ \\ ${ }^{1}$ Irkutsk Scientific Center of the Siberian Branch of the Russian Academy of Sciences (ISC SB RAS), \\ Irkutsk, Russia \\ ${ }^{2}$ Matrosov Institute for System Dynamics and Control Theory of Siberian Branch of Russian \\ Academy of Sciences (IDSTU SB RAS), Irkutsk, Russia
}

\begin{abstract}
In this work, the authors present a technology for riverside terrain model building that has been tested on a number of scientific projects to study the littoral area of tail race of the Irkutsk Hydroelectric Power Station and the Bratsk Reservoir. This model is used for forecasting changes in the reservoir shorelines associated with wastewater in the cascade of hydroelectric power stations. The technology described in the work was approved to solve a number of practical problems and showed its effectiveness. Specialized application software was developed and terrain data from various sources were used to specify and detail the end result.
\end{abstract}

The Angara is a river in Eastern Siberia, the largest right feeder of the Yenisei, the only river flowing out of Lake Baikal. The Angara flows on the territory of the Irkutsk region and Krasnoyarsk territory.

The length of the Angara river is $1779 \mathrm{~km}$, the catchment area of the river 1039000 square meters. Total river fall is 380 meters, its slope is $0,2 \mathrm{~m} / \mathrm{km}$.

Normal annual water flow at the source of the Angara is $1950 \mathrm{~m} 3 / \mathrm{sec}$. Water consumption in the Angara remains high throughout the year and that is very important for the power system. As a result of the flow control by the Irkutsk, Bratsk and Ust-Ilimsk water storage basins, a redistribution of water consumption took place: in the period of shallow water they significantly increased, and during high water periods they decreased.

With a relatively short length, the Angara has a significant drop equal to $380 \mathrm{~m}$ and a large hydropower potential.

On the banks of the Angara there are such large cities as: Irkutsk, Angarsk, Usolye-Sibirskoye, Svirsk, Bratsk, Ust-Ilimsk, Kodinsk and many villages and towns.

The most dangerous area in terms of potential flooding is the zone from the dam of the Irkutsk hydroelectric power station (IHES) to the city of Angarsk with a length of 67 $\mathrm{km}$. About 1 million people live here and the largest enterprises of the Irkutsk region are located. Taking into consideration high risks of urban areas flooding with increased discharges through the stream gauges of Irkutsk power station, it is required to build models to determine the potential zones and boundaries of flooding. Regular space monitoring of

\footnotetext{
* Corresponding author: gachenko@icc.ru
} 
the required area makes it possible to clarify the boundaries of coastlines with an accuracy of several meters, but it is quite costly affair.

With a sufficiently precise relief model it is possible to estimate potential flooding zones and boundaries, taking into account discharges at the Irkutsk HES. In addition, taking into account the period of extreme low water in the basins of Lake Baikal and the river Angara [3] that started in 2014, there was a problem of shallowing boundaries obtaining of the tail-bay of the IHES and the riverside areas of the Bratsk reservoir.

As a result, it became necessary to develop a relief model that takes into consideration the shape of the river bottom.

Using the modern GIS-technologies: QGIS and original software (TINSmith, Fig. 1), with the Delaunay triangulation [1], we modelled zones of the possible flooding during the rise of water level in the HPS water cascade of the Angara River. We identified dangerous sites and settlements threatened under various scenarios of the water content [2, $3]$.

For these methods, the topography from the open sources, SRTM and ALOS, pilot maps and vector map on a scale of 1:50000 were also used. Due to significant inaccuracies of measurements from the open sources near the coastline of water bodies, we decided not to use them and take the terrain from vector topographic maps as a basis.

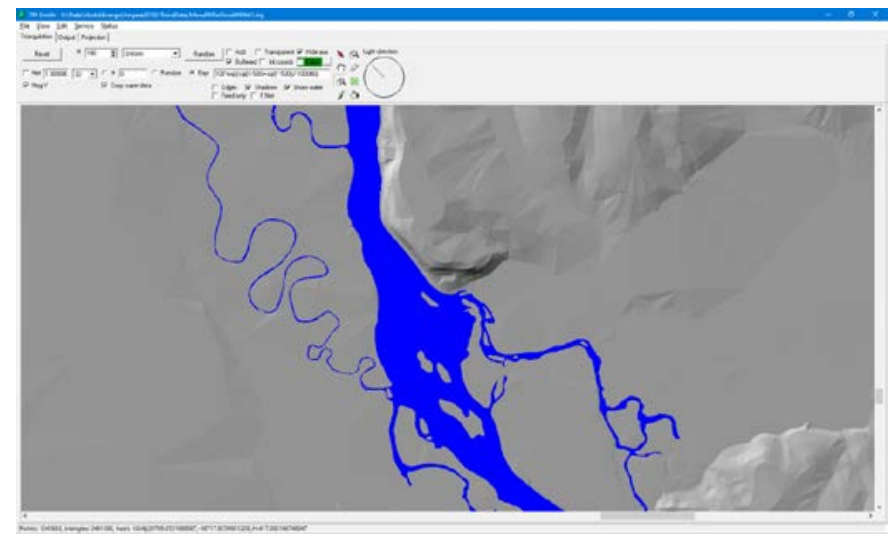

Fig. 1. Special TINSmith software for the Delaunay triangulation.

To generate a topographic model, various layers of the topographic base are used, which can play a different role in triangulation that describes topography. All this is adjusted in a special way in the TINSmith original software: horizontal and vertical control (topography), surfaces of reservoirs (surfaces with a constant height), rivers, and streams (linear and areal objects) are used to correct the topography., the marks of water edges and data on the underwater topography are used in the work with the underwater part. We implemented an algorithm for correcting the topography generated from contour lines. This enables us to correct errors typical of these algorithms: artefacts that create a terrace effect.

At first, we take an underwater topography (the triangulation correction algorithm). We have proposed a technique for terrain and underwater topography, which suggests a separate construction of the underwater topography triangulation. For this, an algorithm of horizontal sites is used. After that, the points and rigid edges of the resulting triangulation are saved to files. These files are used in a combined triangulation. Therefore, the edges added to the triangulation for correction will be included in the final combined triangulation and will correct the stair stepping (terrace) effect. We cannot directly apply 
the triangulation corrections to mixed triangulation because after subtracting the depth from the water level, horizontal triangles become non-horizontal.

For the coordinated combining the contours of the terrain coastline with the vectorized coastline of underwater topography, the problem of matching these lines (topographies) was solved because the underwater topography was obtained from one data and the terrain from other. To solve the problem of verifying reliefs, the model of obtaining a consistent topography was implemented based on the following stages:

1. obtaining source data (vectorization of the printed version of the map in the absence of an electronic version);

2. conversion of the vector topographic base and digitized pilot map to a single coordinate system (WGS 84);

3. setting morphing parameters and conducting morphing itself;

4. obtaining a terrain coordinated with underwater topography.

During morphing (a mechanism for transforming and combining underwater topography with terrain), there is a continuous plane transformation that can combine inaccurate contours of the coastlines with more accurate ones. To combine maps with various types of topography, layers of the coastlines located both in underwater topography and terrain are used. The transformation is applied to various layers of the underwater topography map (isobaths and depth marks). The data resulting from morphing appear to be consistent with the information about terrain.

The contour combining (the problem arises from the inconsistency of terrain with underwater topography) was implemented as a special task in the IrkGV electronic map viewer. The operator working with the program adjusts the parameters in a certain way, which combine the points of the source (inaccurate) and target (accurate) maps. When the contours are combined, the start and end points of the arrows drawn by the user are projected onto the contour points of the corresponding maps nearest to them. Next, a mapping of each contour section of the object on the source map is generated into a specified object on the target map for each pair of arrows that are adjacent on both contours.

The points of contour sections that are combined with each other are displayed through a linear transformation of the parametric coordinates of the curves. If the result obtained is not suitable, then to guarantee the combining some characteristic points of contours, it is necessary to compare these points with each other. After entering information about the combining maps, a file of displacements is formed, in which, in addition to the obviously specified displacements, there are displacements calculated for intermediate points of the contours.

The generation of the topography of the Angara River fragment for a section of $135 \mathrm{~km}$ in the interval from Irkutsk HPS to the town of Svirsk and the Irkutsk Reservoir resulted in obtaining a comprehensive digital model (Fig. 2) of the underwater topography combined with the terrain. A digital elevation model of this kind has been obtained for the first time and has no analogues. 

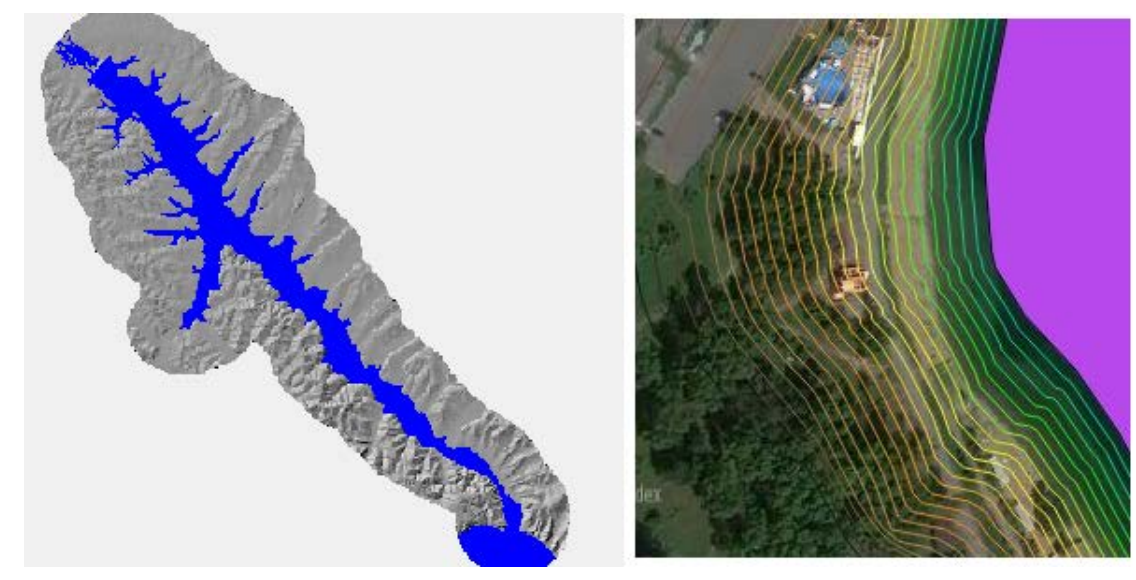

Fig. 2. Triangulation for a given area and an example of possible flooding under various scenarios of the water content (the Irkutsk Reservoir). Contour lines are plotted every $20 \mathrm{~cm}$.

Based on the modelling various scenarios of water level rise using the QGIS standard methods, we obtained an album with maps of the settlements (103 objects) that are subject to flooding. A map with contour lines was generated for the level rise of up to $5 \mathrm{~m}$ and contour lines every $20 \mathrm{~cm}$ (Figs 2-4). An expert assessment of the risks of the possible flooding was carried out for each settlement.

Based on the technique described above, we developed digital elevation models of the Irkutsk, Bratsk and Ust-Ilimsk reservoirs (Figs 2-4), including the zones of possible flooding (in the form of contour lines) under various scenarios of the water content. Based on this technique, we generated an electronic map of the coastline (buffer zone from 4 to 10 $\mathrm{km}$ ) and obtained a digital album for the Angara River within the Irkutsk Region. We processed 103 settlements within the Irkutsk Region and constructed contour lines with flooding threat levels for each of them.

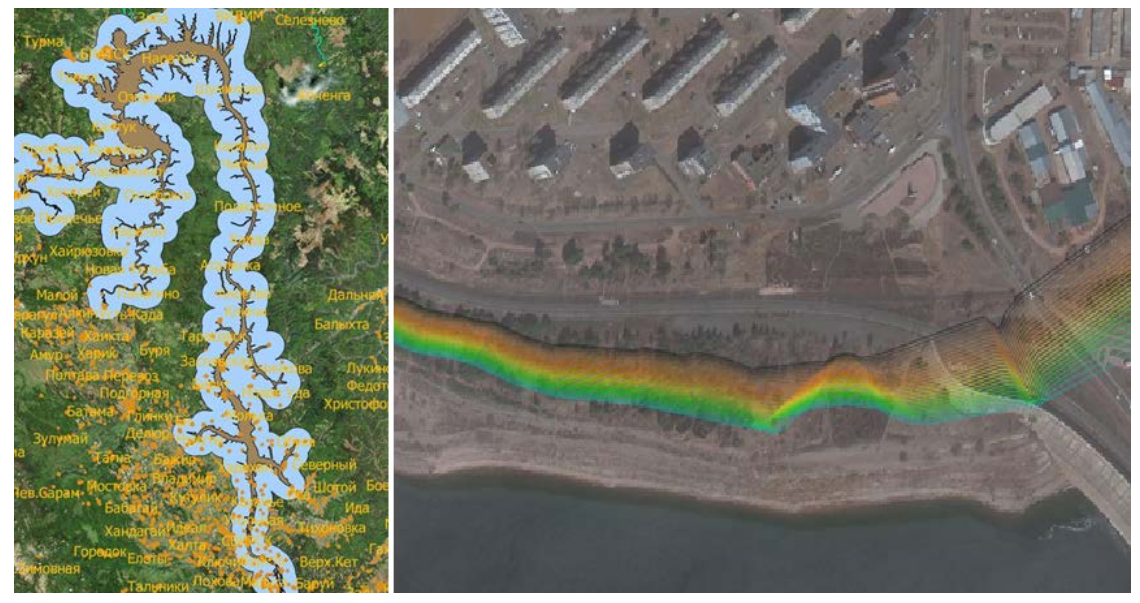

Fig. 3. The Bratsk Reservoir and a fragment of the Bratsk city. 


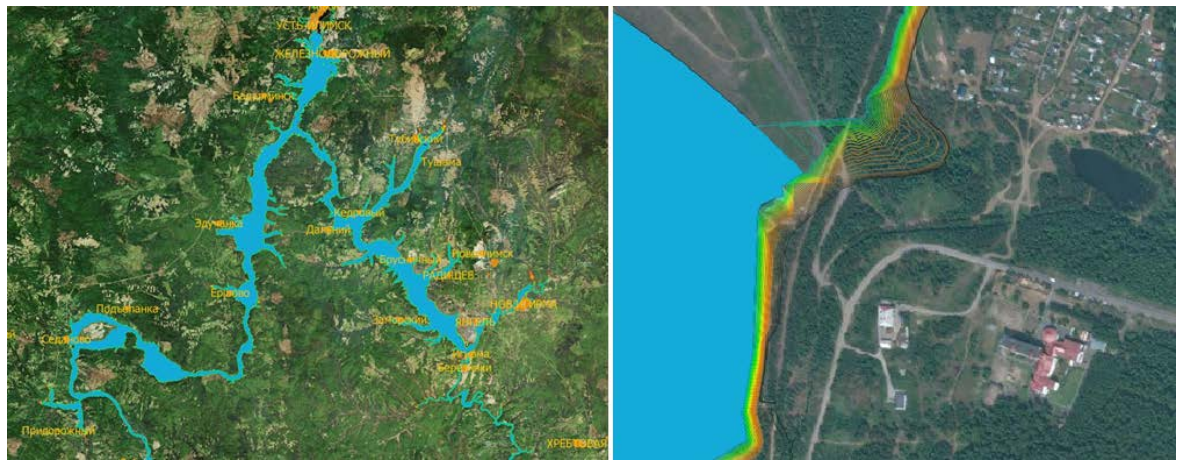

Fig. 4. The Ust-Ilimsk Reservoir and the fragment of the Ust-Ilimsk town.

In conditions of elevated and extremely high influx to Lake Baikal, taking into account the current rules for regulating water levels in the lake, there are high risks of flooding in the downstream of Irkutsk HPS. To assess the possible damage, we have developed a technique for modelling the channel of the Angara River as well as special software components that allow us to investigate flooding zones at various discharges through HPS.

Using this technique and the developed digital elevation model, we can make various forecasts about the scenarios and threats under different water level regimes for all settlements adjacent to the bank of the Angara River in the section from the river source to the Bratsk Reservoir. We have identified dangerous sites and settlements that are threatened under various scenarios of the water content.

The work was carried out with the support of RAS (projects:AAAA-A17-117032210079-1, AAAA-A19-119111990037-0) and framework of the block of the ISC SB RAS integration program 4.1.2.

\section{Reference}

1. A. V. Skvortsov 2002 Delaunay triangulation and its appliance (Tomsk: Tomsk University press) p 128.

2. I. V. Bychkov and V. M. Nikitin Control of level of Lake Baikal: problems and possible issues Geography and environmental resources 3 pp 5-16 (2015).

3. N. V. Abasov, M. V. Bolgov, V. M. Nikitin and E. N. Osipchuk On regulation of the urovenny mode of Lake Baikal Water Resources 44 pp 407-416 (2017). 